\title{
Anomalies of binocular function in patients with longstanding asymmetric keratoconus
}

\author{
Hooman Sherafat, Joy E S White, Kenneth W Pullum, Gillian G W Adams, John J Sloper
}

Strabismus and

Paediatric Service, Moorfields Eye

Hospital, City Road, London EC1V 2PD,

UK

H Sherafat

JE S White

G G W Adams

J J Sloper K W Pullum

Correspondence to: Mr J Sloper

john.sloper@dial.pipex.com

Accepted for publication 4 April 2001
Contact Lens Service

\begin{abstract}
Aims-To study binocular function in patients with longstanding asymmetric keratoconus.

Methods-In 20 adult patients with longstanding asymmetric keratoconus managed with a scleral contact lens a full clinical and orthoptic assessment was performed with and without the scleral contact lens in the poorer eye.

Results-All 20 patients had a corrected acuity of at least $6 / 9$ in their better eye. With the scleral lens in situ the acuity of the poorer eye ranged from $6 / 6$ to $6 / 60$ and without the lens from $6 / 18$ to hand movements. Patients were aged from 18 to 68 years and had worn a scleral contact lens for between 3 and 106 months. Without the contact lens in their poorer eye all patients had a small exotropia and all showed suppression, with the exception of one patient who had a right hypertropia with diplopia. With the scleral lens in situ 12 patients had an exophoria or esophoria, six a microexotropia, and two a manifest exotropia with suppression.

Conclusions-Binocular function breaks down in some adult patients with longstanding asymmetric keratoconus. This is probably caused by longstanding unilateral visual deprivation. There are similarities to the breakdown of binocular function seen in some patients with a longstanding dense unilateral adult onset cataract who can develop intractable diplopia following cataract surgery. (Br f Ophthalmol 2001;85:1057-1060)
\end{abstract}

Table 1 Details of patients with keratoconus

\begin{tabular}{llllllc}
\hline Patient & Sex & Age (years) & $\begin{array}{c}\text { Time from } \\
\text { diagnosis } \\
\text { (years) }\end{array}$ & Fixing eye & $\begin{array}{l}\text { Fixing eye } \\
\text { correction }\end{array}$ & $\begin{array}{l}\text { Duration scleral lens } \\
\text { wear in affected eye } \\
\text { (months) }\end{array}$ \\
\hline 1 & M & 18 & 6 & Right & Corneal CL & 30 \\
2 & M & 18 & 3 & Left & Corneal CL & 31 \\
3 & M & 18 & 6 & Left & Corneal CL & 40 \\
4 & M & 26 & 8 & Right & Corneal CL & 8 \\
5 & M & 27 & 12 & Left & Corneal CL & 92 \\
6 & F & 28 & 10 & Right & Scleral CL+PK & 27 \\
7 & M & 29 & 10 & Left & Scleral CL & 40 \\
8 & F & 30 & 8 & Right & Corneal CL & 7 \\
9 & M & 32 & 18 & Left & Scleral CL+PK & 41 \\
10 & M & 35 & 12 & Right & Corneal CL & 9 \\
11 & F & 36 & 18 & Left & Corneal CL & 27 \\
12 & M & 36 & 17 & Right & Unaided & 48 \\
13 & M & 37 & 11 & Right & Corneal CL & 106 \\
14 & F & 40 & 14 & Right & Corneal CL & 62 \\
15 & M & 44 & 19 & Right & Spectacle & 30 \\
16 & F & 47 & 32 & Right & Corneal CL & 60 \\
17 & F & 51 & 28 & Right & Corneal CL & 90 \\
18 & F & 64 & 34 & Left & Spectacle & 3 \\
19 & F & 65 & 50 & Left & Corneal CL & 48 \\
20 & F & 68 & 51 & Left & Scleral CL & 66 \\
\hline
\end{tabular}

$\mathrm{CL}=$ contact lens; $\mathrm{PK}=$ penetrating keratoplasty.
This study was prompted by the clinical observation that some patients with longstanding asymmetric keratoconus chose to wear a scleral contact lens in their poorer eye, even though the corrected vision of this eye was still substantially worse than that of their better eye. This suggested that their binocular function was improved by wearing the lens. A group of such patients was therefore investigated using clinical tests of binocular function. These demonstrated striking abnormalities in their binocular function, which were reduced with the contact lens in situ. These changes are probably due to the longstanding, mainly unilateral, visual impairment resulting from their asymmetric keratoconus. There appear to be no previous reports of abnormalities of binocular function in patients with keratoconus.

These data were presented at the 25th Annual Conference of the European Strabismological Association, Jerusalem, September 1999. ${ }^{1}$

\section{Methods}

From a database of approximately 350 patients with keratoconus being managed with a scleral contact lens, 35 were identified as having a corrected acuity with the scleral lens in their more affected eye which was two or more Snellen lines worse than their fellow eye. Twenty of these 35 patients were recruited for this study. Visual correction was not possible with conventional contact lenses in these patients with very marked keratoconus, as a stable fit could not be achieved. However, a stable fit had been achieved with a rigid gas permeable scleral lenses and these were well tolerated. ${ }^{2}$ Because of the irregularity of the cornea in advanced keratoconus and because scleral lenses use the fluid lens between the posterior lens surface and the corneal surface to produce emmetropia, it is not possible to give meaningful refractive data for the patients. However, all were emmetropic with their lens in situ.

Snellen visual acuities were measured with and without the contact lens. Binocular function was assessed with and without the scleral lens in their poorer eye using the cover test, prism cover test, Bagolini glasses, and prism fusion range at 6 metres and $1 / 3$ metre. Stereopsis was initially tested using the TNO test; if a patient failed to demonstrate any stereopsis with this method the Titmus test was used to look for the presence of gross stereopsis. The 4 dioptre base-out prism test was used to test for central suppression and aniseikonia was assessed using the Awaya Aniseikonia test and/or Rubens slides on the synoptophore. A microtropia was defined as a manifest squint of 


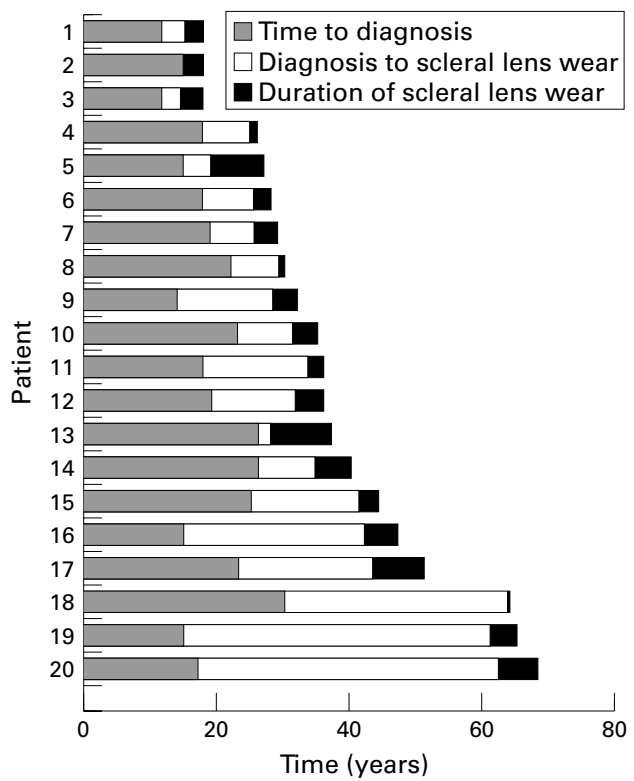

Figure 1 Age at diagnosis of keratoconus, duration of disease, and duration of scleral contact lens wear for 20 patients.

10 prism dioptres or less, with evidence of anomalous binocular function.

\section{Results}

The 20 patients studied were from 18 to 68 years old. The diagnosis of keratoconus had been made between 3 and 51 years previously and the patients had worn a scleral lens for between 3 months and almost 9 years (Table 1, Fig 1). All patients had a corrected acuity of at least $6 / 9$ in their better, fixing eye, in most cases by using a corneal contact lens (Tables 1 and 2 ). Acuities with the scleral lens in their poorer eye ranged from $6 / 6$ to $6 / 60$ and without the lens from 6/18 to hand movements (Table 2).

Without the scleral lens all 20 patients had a manifest squint with absent binocular function (Table 2). Nineteen patients showed suppression of their poorer eye when tested with Bagolini glasses and one had diplopia and a small manifest vertical deviation. All except one were exotropic, although the angles were small and not cosmetically obvious. In most patients it was not possible accurately to measure the angle of the squint by cover test as fixation with the affected eye was poor. An abnormal angle kappa was recorded in 15 cases. The corneal reflections were either temporally displaced giving rise to a pseudo-esotropia, inferiorly displaced giving rise to a pseudohypertropia or a combination of both.

With the scleral lens in their poorer eye, 16 of the 20 patients showed evidence of binocular single vision with Bagolini glasses and 14 had measurable stereoacuity. In four patients this was only gross stereopsis and only one patient achieved a stereoacuity of 60 seconds of arc (Table 2). No patient overcame a 4 dioptre prism placed in front of the more affected eye, indicating the presence of a central suppression area. On cover test 12 patients had a phoria, six a microexotropia, and two a manifest exotropia (Table 2). There was an associated vertical deviation on distance testing in 12 of the cases and for near in 10 cases (Table 3). Sixteen patients had a measurable motor fusion range at 6 metres and 17 at $1 / 3$ metre (Table 3). Only one patient gave a history of any previous orthoptic treatment as a child and this patient had one of the best stereoacuities.

No patient reported significant aniseikonia when tested using their scleral lens; this could not be tested without the contact lens because of suppression.

\section{Discussion}

This study describes 20 patients with longstanding asymmetric keratoconus who all showed evidence of grossly abnormal binocular function by standard orthoptic tests. With a scleral contact lens in their poorer eye most achieved a degree of binocular single vision. Without the scleral lens no patient showed any evidence of binocular function and all except one suppressed the deviating eye. The patients thus gained a substantial functional advantage

Table 2 Visual acuity and binocular function with and without scleral lens in situ

\begin{tabular}{|c|c|c|c|c|c|c|c|c|}
\hline \multirow[b]{2}{*}{ Patient } & \multirow[b]{2}{*}{$\begin{array}{l}\text { Fixing eye } \\
\text { acuity }\end{array}$} & \multicolumn{4}{|c|}{ Affected eye with scleral lens in situ } & \multicolumn{3}{|c|}{ Affected eye without scleral lens } \\
\hline & & Acuity & Binocular function & $\begin{array}{l}\text { Bagolini } \\
\text { glasses }\end{array}$ & $\begin{array}{l}\text { Stereopsis } \\
\text { (seconds of arc) }\end{array}$ & Acuity & Binocular function & $\begin{array}{l}\text { Bagolini } \\
\text { glasses }\end{array}$ \\
\hline 1 & $6 / 6$ & $6 / 24$ & Exophoria & Suppression & $200(w)$ & $3 / 60$ & Exotropia + R/L & Suppression \\
\hline 2 & $6 / 9$ & $6 / 36$ & Microexotropia & BSV & NIL & $\mathrm{CF}$ & Exotropia & Suppression \\
\hline 3 & $6 / 6$ & $6 / 18$ & Microexotropia & BSV & NIL & $1 / 60$ & Exotropia & Suppression \\
\hline 4 & $6 / 9$ & $6 / 36$ & Exophoria & BSV & $200(w)$ & $\mathrm{CF}$ & Exotropia & Suppression \\
\hline 5 & $6 / 9$ & $6 / 60$ & Microexotropia & BSV & Gross (w) & $1 / 120$ & Exotropia & Suppression \\
\hline 6 & $6 / 6$ & $6 / 24$ & Microexotropia & BSV & NIL & $\mathrm{CF}$ & Exotropia & Suppression \\
\hline 7 & $6 / 6$ & $6 / 36$ & Microexotropia & BSV & 480 & $1 / 120$ & Exotropia & Suppression \\
\hline 8 & $6 / 9$ & $6 / 24$ & Exophoria & BSV & NIL & $\mathrm{HM}$ & $\mathrm{R} / \mathrm{L}$ & Diplopia \\
\hline 9 & $6 / 5$ & $6 / 18$ & Exophoria & BSV & 120 & $1 / 120$ & Exotropia & Suppression \\
\hline 10 & $6 / 5$ & $6 / 18$ & Exophoria & BSV & 60 & $1 / 60$ & Exotropia & Suppression \\
\hline 11 & $6 / 6$ & $6 / 18$ & Esophoria & BSV & 240 & $\mathrm{CF}$ & Exotropia & Suppression \\
\hline 12 & $6 / 4$ & $6 / 18$ & Exotropia & Suppression & NIL & $\mathrm{CF}$ & Exotropia & Suppression \\
\hline 13 & $6 / 5$ & $6 / 18$ & Esophoria & BSV & Gross (w) & $1 / 60$ & Exotropia & Suppression \\
\hline 14 & $6 / 9$ & $6 / 12$ & Exophoria & BSV & 480 & $\mathrm{CF}$ & Exotropia & Suppression \\
\hline 15 & $6 / 5$ & $6 / 6$ & Exophoria & BSV & 480 & $6 / 18$ & Exotropia & Suppression \\
\hline 16 & $6 / 6$ & $6 / 36$ & Exotropia & Suppression & NIL & $\mathrm{CF}$ & Exotropia & Suppression \\
\hline 17 & $6 / 6$ & $6 / 12$ & Exophoria & BSV & 240 & $1 / 60$ & Exotropia & Suppression \\
\hline 18 & $6 / 9$ & $6 / 24$ & Exophoria & BSV & $200(w)$ & $\mathrm{CF}$ & Exotropia & Suppression \\
\hline 19 & $6 / 6$ & $6 / 24$ & Exophoria & Suppression & Gross (w) & $1 / 60$ & Exotropia & Suppression \\
\hline 20 & $6 / 9$ & $6 / 24$ & Microexotropia & BSV & Gross (w) & $\mathrm{HM}$ & Exotropia & Suppression \\
\hline
\end{tabular}

$\mathrm{BSV}=$ binocular single vision; $(\mathrm{w})=$ Wirt stereotest, otherwise $\mathrm{TNO} ; \mathrm{CF}=$ counting fingers; $\mathrm{HM}=$ hand movements; $\mathrm{R} / \mathrm{L}=$ right over left. 
Table 3 Details of orthoptic findings

\begin{tabular}{|c|c|c|c|c|c|c|c|c|}
\hline \multirow{3}{*}{$\frac{\text { Patient }}{1}$} & \multicolumn{4}{|c|}{ Prism cover test with scleral lens } & \multicolumn{2}{|c|}{ Prism fusion range with scleral lens } & \multirow{3}{*}{$\begin{array}{l}4 \text { Dioptre base-out prism } \\
\text { Not overcome }\end{array}$} & \multirow{3}{*}{$\begin{array}{l}\begin{array}{l}\text { Previous } \\
\text { ophthalmic } \\
\text { history }\end{array} \\
\text { Patched }\end{array}$} \\
\hline & \multicolumn{2}{|c|}{6 metres (prism dioptres) } & \multicolumn{2}{|c|}{$1 / 3$ metre (prism dioptres) } & \multirow{2}{*}{$\begin{array}{l}6 \text { metres (prism dioptres) } \\
10 \mathrm{PBO}-4 \mathrm{PBI}\end{array}$} & \multirow{2}{*}{$\frac{1 / 3 \text { metre (prism dioptres) }}{40 \mathrm{PBO}-4 \mathrm{PBI}}$} & & \\
\hline & $1 \mathrm{XT}$ & $1 \mathrm{R} / \mathrm{L}$ & $4 \mathrm{XT}$ & $1 \mathrm{R} / \mathrm{L}$ & & & & \\
\hline 2 & $4 \mathrm{XT}$ & & $16 \mathrm{XT}$ & & $4 \mathrm{PBO}-6 \mathrm{PBI}$ & $16 \mathrm{PBO}-14 \mathrm{PBI}$ & Not overcome & None \\
\hline 3 & $12 \mathrm{XT}$ & & $8 \mathrm{XT}$ & & NIL & NIL & Not overcome & None \\
\hline 4 & $2 \mathrm{XT}$ & & $8 \mathrm{XT}$ & & $12 \mathrm{PBO}-2 \mathrm{PBI}$ & $25 \mathrm{PBO}-8 \mathrm{PBI}$ & Not overcome & None \\
\hline 5 & $16 \mathrm{XT}$ & $2 \mathrm{~L} / \mathrm{R}$ & $16 \mathrm{XT}$ & $2 \mathrm{~L} / \mathrm{R}$ & $6 \mathrm{PBO}-2 \mathrm{PBI}$ & 6 PBO-2 PBI & Not overcome & None \\
\hline 6 & $1 \mathrm{XT}$ & $1 \mathrm{~L} / \mathrm{R}$ & $4 \mathrm{XT}$ & $1 \mathrm{~L} / \mathrm{R}$ & NIL & $18 \mathrm{PBO}-8 \mathrm{PBI}$ & Not overcome & PK \\
\hline 7 & $4 \mathrm{XT}$ & $2 \mathrm{R} / \mathrm{L}$ & $10 \mathrm{XT}$ & & $6 \mathrm{PBO}-1 \mathrm{PBI}$ & $6 \mathrm{PBO}-1 \mathrm{PBI}$ & Not overcome & None \\
\hline 8 & $4 \mathrm{XT}$ & $2 \mathrm{R} / \mathrm{L}$ & $6 \mathrm{XT}$ & & $16 \mathrm{PBO}-6 \mathrm{PBI}$ & $35 \mathrm{PBO}-10 \mathrm{PBI}$ & Not overcome & None \\
\hline 9 & $2 \mathrm{XT}$ & $2 \mathrm{~L} / \mathrm{R}$ & $8 \mathrm{XT}$ & $2 \mathrm{~L} / \mathrm{R}$ & $10 \mathrm{PBO}-8 \mathrm{PBI}$ & $20 \mathrm{PBO}-16 \mathrm{PBI}$ & Not overcome & PK \\
\hline 10 & $1 \mathrm{XT}$ & & $4 \mathrm{XT}$ & & $16 \mathrm{PBO}-8 \mathrm{PBI}$ & $35 \mathrm{PBO}-10 \mathrm{PBI}$ & Not overcome & None \\
\hline 11 & $2 \mathrm{ET}$ & $1 \mathrm{R} / \mathrm{L}$ & $4 \mathrm{XT}$ & $1 \mathrm{R} / \mathrm{L}$ & $20 \mathrm{PBO}-2 \mathrm{PBI}$ & $45 \mathrm{PBO}-16 \mathrm{PBI}$ & Not overcome & None \\
\hline 12 & $6 \mathrm{XT}$ & & $16 \mathrm{XT}$ & & NIL & NIL & Not binocular & None \\
\hline 13 & $1 \mathrm{ET}$ & $2 \mathrm{~L} / \mathrm{R}$ & $2 \mathrm{XT}$ & $3 \mathrm{~L} / \mathrm{R}$ & $16 \mathrm{PBO}-4 \mathrm{PBI}$ & $30 \mathrm{PBO}-14 \mathrm{PBI}$ & Not overcome & None \\
\hline 14 & $1 \mathrm{XT}$ & & $1 \mathrm{XT}$ & & $20 \mathrm{PBO}-8 \mathrm{PBI}$ & $40 \mathrm{PBO}-16 \mathrm{PBI}$ & Not overcome & None \\
\hline 15 & 0 & $4 \mathrm{R} / \mathrm{L}$ & $6 \mathrm{XT}$ & $2 \mathrm{R} / \mathrm{L}$ & $16 \mathrm{PBO}-6 \mathrm{PBI}$ & $30 \mathrm{PBO}-14 \mathrm{PBI}$ & Not overcome & None \\
\hline 16 & $6 \mathrm{XT}$ & & $4 \mathrm{XT}$ & & NIL & NIL & Not binocular & None \\
\hline 17 & $2 \mathrm{XT}$ & $1 \mathrm{R} / \mathrm{L}$ & $8 \mathrm{XT}$ & $2 \mathrm{R} / \mathrm{L}$ & $6 \mathrm{PBO}-6 \mathrm{PBI}$ & $25 \mathrm{PBO}-14 \mathrm{PBI}$ & Not overcome & None \\
\hline 18 & $20 \mathrm{XT}$ & $6 \mathrm{R} / \mathrm{L}$ & $4 \mathrm{XT}$ & $2 \mathrm{R} / \mathrm{L}$ & $20 \mathrm{PBO}-10 \mathrm{PBI}$ & $20 \mathrm{PBO}-12 \mathrm{PBI}$ & Not overcome & None \\
\hline 19 & 0 & $1 \mathrm{~L} / \mathrm{R}$ & $6 \mathrm{XT}$ & $2 \mathrm{~L} / \mathrm{R}$ & $12 \mathrm{PBO}-4 \mathrm{PBI}$ & $30 \mathrm{PBO}-10 \mathrm{PBI}$ & Not overcome & None \\
\hline 20 & $1 \mathrm{XT}$ & & $10 \mathrm{XT}$ & & $2 \mathrm{PBO}-4 \mathrm{PBI}$ & $4 \mathrm{PBO}-4 \mathrm{PBI}$ & Not overcome & None \\
\hline
\end{tabular}

$\mathrm{XT}=$ exodeviation $; \mathrm{ET}=$ esodeviation $\mathrm{PBO}=$ prism base out $\mathrm{PBI}=$ prism base in $\mathrm{PK}=$ penetrating keratoplasty to fellow eye; $\mathrm{R} / \mathrm{L}=$ right over left $\mathrm{L} / \mathrm{R}=$ left over right.

from wearing their scleral lens and this almost certainly explains their enthusiasm for doing so.

To our knowledge there are no previous reports of abnormal binocular function in patients with keratoconus. The patients in the present study all had longstanding keratoconus in which both the uncorrected and corrected acuity of one eye was substantially poorer than that of the other. They were recruited from a pool of about 350 patients with keratoconus managed with scleral contact lenses. All 20 patients subjectively found an advantage in wearing a scleral lens in their worse eye and were found to have anomalous binocular function on formal testing. The anomalies in these patients were not readily apparent without formal testing of binocular function because the squint angles were small and the corneal distortion found in keratoconus or the presence of a contact lens may give rise to abnormally aligned corneal reflexes. Most patients suppressed the deviating eye when manifest and so did not complain of diplopia. It is possible that anomalous binocular function is not uncommon in patients with longstanding keratoconus.

Uniocular optical blur alone reduces stereoacuity in normal subjects. ${ }^{34}$ These studies used induced anisometropia to cause blur, which would also produce aniseikonia. Because of the advanced keratoconus and the way in which scleral lenses produce their correction by using the fluid lens between the scleral lens and a very irregular cornea, it was not possible to obtain meaningful refractive data for the present patients. However, all were emmetropic with their scleral lenses in situ and were shown not to be aniseikonic. Nevertheless, for an equivalent reduction in acuity of the poorer eye, stereoacuity was more reduced in the keratoconic patients than in normal subjects with optically reduced acuity in one eye (Fig 2 ). Of the 14 normal subjects studied by Goodwin and Romano, ${ }^{4}$ none lost stereoacuity altogether until the acuity of the worse eye was reduced to $20 / 200$, even though they also had induced anisometropia. By comparison, six of the present 20 keratoconic patients had no stereopsis with their contact lens in situ at acuities of between $6 / 18$ and $6 / 36$ (20/60 to 20/120) (Table 2). A statistical comparison of the stereoacuities of the 18 keratoconic subjects who had acuities of between $6 / 12$ and $6 / 36$ with the values for the normal subjects with the nearest equivalent acuities of between 20/40 and 20/100 in Goodwin and Romano's study, ${ }^{4}$ show the keratoconic subjects to have a significantly worse stereoacuity (keratoconic median 3000 seconds of arc, normal 400 seconds of arc; $p<0.02$, Mann-Whitney U test). The mean stereoacuities of the normal subjects studied by Levy and Glick ${ }^{3}$ were substantially better at each Snellen acuity than the median values of Goodwin and Romano and so the keratoconic subjects were even more abnormal compared to this group (Fig 2). Although such comparisons must be treated with considerable caution, it would appear that stereoacuity in the keratoconic subjects is substantially worse than can be accounted for by reduced acuity alone.

More striking is the observation that six of the 20 keratoconic patients had a microexotropia (with anomalous binocular function)

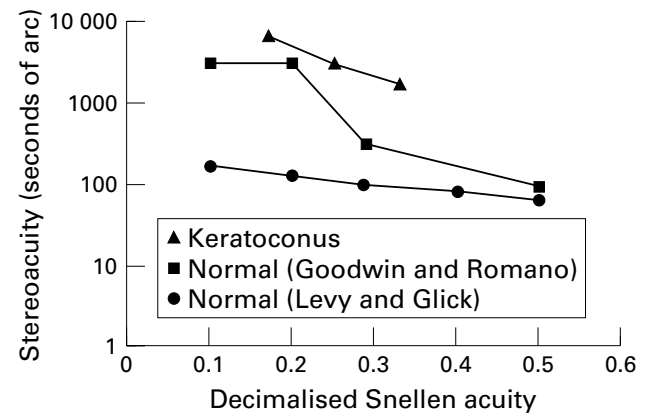

Figure 2 Comparing the median stereoacuity for Snellen acuities of the poorer eye between 6/12 and 6/60 (20/40 and 20/200) in 20 patients with longstanding asymmetric keratoconus with those for 14 normal subjects taken from table 1 of Goodwin and Romano 4 and the mean stereoacuities for 10 normal subjects with a comparable acuity difference from Levy and Glick. ${ }^{3}$ 
and two a manifest exotropia (with suppression) with their contact lens in situ. Goodwin and Romano ${ }^{4}$ specifically looked for tropias during testing of their normal subjects and found none and none were noted by Levy and Glick. ${ }^{3}$ A further study which examined the relation between the degree of induced anisometropia and binocular function in normal subjects found only occasional minor abnormalities such as brief suppression with an induced difference of 2-3 dioptres, ${ }^{5}$ but nothing close to the degree of binocular disruption found in the present patients.

Although there is no direct evidence that the patients described here had normal binocular function prior to the development of their keratoconus, only one of the patients had a known history of squint, amblyopia or poor vision in the affected eye. Although microtropias may go unrecognised in childhood, they are relatively uncommon within the overall population with squints, and it seems unlikely that at least 20 of the 350 patients with keratoconus all had previously unrecognised microtropias. The abnormalities described here follow a consistent pattern, with central suppression of the deviating eye, reduction or loss of stereopsis with a microtropia when wearing their scleral lens, and a manifest exotropia with suppression when the poorer eye is uncorrected. It seems most likely that some at least of these changes are due to prolonged deprivation of form vision in the poorer eye from the asymmetric keratoconus.

It has generally been assumed that the sensitive period during which abnormal visual experience affects visual development in humans finishes at about 7 years of age and that the adult visual system is not affected by visual deprivation in animals or humans..$^{6-10}$ The earliest age at which keratoconus was diagnosed in our series of patients was 12 years, and in most it was considerably later and well into adulthood (Fig 1). However, it has been shown that patients with longstanding, dense monocular cataracts of adult onset show a marked delay in visual evoked potentials recorded to stimulation of the deprived eye following cataract extraction. ${ }^{11}$ In most cases this resolved over a period of months, but longstanding, monocular visual deprivation associated with adult onset cataracts can result in an irreversible loss of binocular function, with intractable diplopia following cataract surgery. ${ }^{12-14}$ Suppression is often considered to occur only in squints of childhood onset, but we have observed it in patients with longstanding adult onset squints from cranial nerve palsies and thyroid eye disease and so its presence does not necessarily demonstrate the onset of a binocular anomaly in childhood. The above findings indicate that the adult visual system is susceptible to prolonged visual deprivation and the present patients would appear to be another instance of this. It will be of considerable interest to see if they have comparable abnormalities in their visual evoked responses to those found in the patients with longstanding unilateral cataracts.

It is probable that the patients described here developed their anomalous binocular function because of prolonged reduced acuity in one eye from their keratoconus. In most instances scleral lenses were introduced into their management at a fairly late stage in the disease. It is possible that earlier correction of their poorer eye would have preserved better binocular function. Even when anomalous binocular function has developed it is clear that even a limited improvement in acuity in the poorer eye from using a scleral lens can have a substantial impact on the overall visual function of a patient.

Proprietary interests: KP manufactures and supplies scleral contact lenses.

Grant support: None. 1 White JES, Adams GGW, Sherafat $\mathrm{H}$, et al. Binocular func-
tions in patients with keratoconus managed with scleral tions in patients with keratoconus managed with scleral
contact lenses. Transactions of the 25 th Meeting of the contact lenses. Transactions of the 25th Meeting of the
European Strabismological Association, 1999, Jerusalem. European Strabismological Associat
Lisse, Netherlands: Aeolus Press

Lisse, Netherlands: Aeolus Press.
2 Pullum KW, Buckley, RJ. A study of 530 patients referred for rigid gas permeable scleral contact lens assessment. Cornea 1997;16:612-22.

3 Levy NS, Glick EB. Stereoscopic perception and Snellen visual acuity. Am f Ophthalmol 1974;78:722-4.

4 Goodwin RT, Romano PE. Stereoacuity degradation by experimental and real monocular and binocular amblyopia. Invest Ophthalmol Vis Sci 1985;26:917-23.

5 Brooks SE, Johnson D, Fischer N. Anisometropia and binocularity. Ophthalmology 1996;103:1139-43.

6 Boothe RG, Dobson V, Teller DY. Postnatal development of vision in human and non-human primates. Ann Rev Neurosci 1985;8:485-545.

7 Von Noorden GK. Amblyopia: a multidisciplinary approach. Invest Ophthalmol Vis Sci 1985;26:1704-16.

8 Wiesel TN. Postnatal development of the visual cortex and the influence of environment. Nature 1982;299:583-91.

9 Sloper JJ. Competition and co-operation in visual development. Eye 1993;7:319-31.

10 Vaegan, Taylor D. Critical period for deprivation amblyopia in children. Trans Ophthal Soc UK 1979;99:432-9.

1 Sloper JJ, Collins AD. Delayed visual evoked potentials in adults after monocular visual deprivation by a dense cataract. Invest Ophthalmol Vis Sci 1995;36:2663-71.

12 Hamed LM, Helveston EM, Ellis FD. Persistent binocular diplopia after cataract surgery. Am $\mathcal{F}$ Ophthalmol 1977;103: 741-4.

13 Pratt-Johnson JA, Tillson G. Intractable diplopia after vision restoration in unilateral cataract. Am $\mathcal{f}$ Ophthalmol 1989;107:23-6.

14 Sharkey JA, Sellars PW. Acquired central fusion disruption following cataract extraction. $\mathcal{F}$ Paediatr Ophthalmol Strabismus 1994;391-3. 